\title{
Leeches: A Review on their Pathogenic and Beneficial Effects
}

Desta Aloto ${ }^{1}$ and Eyob Eticha ${ }^{2 *}$

${ }^{1}$ Veterinary Drug and Animal Feed Administration and Control Authority, South Region Branch Office, Hawassa, Ethiopia

${ }^{2}$ Asella Regional Veterinary Laboratory, PO Box 212, Ethiopia

*Corresponding author: Eyob Eticha, Asella Regional Veterinary Laboratory, PO Box 212, Ethiopia, Tel: +251913178237; E-mail: eyoba20000@gmail.com

Rec date: December 23, 2017; Acc date: January 23, 2018; Pub date: January 24, 2018

Copyright: (C) 2018 Aloto D, et al. This is an open-access article distributed under the terms of the Creative Commons Attribution License, which permits unrestricted use, distribution, and reproduction in any medium, provided the original author and source are credited.

\begin{abstract}
Leech is one of the external sanguivorous parasites contributing to the reduction in productivity of livestock in different part of the World. Leeches bite the skin of the host and allow copious flow of blood preventing clot by hirudin. The bite is not painful, but the wounds may bleed for a long time and the clinical signs can be seen following this blood loss. Types of leech vary depending on ways by which they feed. Leech is segmented and lacks as hard exoskeleton; in its place it has a thin, flexible cuticle. For the most part leeches are aquatic, but terrestrial species are also found. Leeches are hermaphroditic and their feed relationships are varied. Hirudo medicinalis is the most known medicinal leech. Diagnosis can be made from clinical signs and finding the parasite in the bite area. Triclorfon, chloroform water, neguvon solution, mechanical removal, and tracheotomy in extreme cases are the best treatment approaches. Avoiding leech, depopulating infected water bodies and application of 'endod' to watering points are some methods of control and prevention.
\end{abstract}

Keywords: Leeches; Hirudo medicinalis, Endod; Hermaphroditic

\section{Introduction}

Leeches are of worldwide distribution and are extremely abundant both in species and the number of individuals $[1,2]$. Leeches make up a third large group of annelids, which are blood feeding ectoparasites of man, wild and domesticated animals, but about $25 \%$ of the species of leeches are predators of small invertebrates. Most predator leeches feed on worms, snails, and insect larvae [3,4]. Leech possessing prominent suckers, grips the surface of the prey while it sucks the victim's blood. Located within the anterior sucker, the leech's mouth is equipped with a set of razor-sharp jaws that open a wound in the prey, while the muscular pharynx pumps the blood into the leech's digestive tract. A salivary gland, secrete a substance, hirudin, that prevent coagulation of the blood $[5,6]$.

Leeches, class Hirudinea, are distinguished from other annelids by having; a sucker or sucker like depression at the anterior end of the body and a well-developed sucker at the posterior end, a constant number of body segments (34), no setae or Para podia except in Acanthobdella, and a body cavity largely filled with muscles and connective tissue $[4,7,8]$.

Most species of leech live in fresh water or terrestrial habitat and some in marine water. Land leeches are found on the surfaces of the trees and grasses and under stones in damp places [9].

Leeches used to be widely employed in medicine for bloodletting. Even today they are used to reduce fluid pressure in tissues damaged by, for example, a snake bite and to eliminate pools of coagulated blood $[10,11]$.

Leeches are hermaphroditic, but need cross fertilization and they copulate to reproduce. They have excretory organs, nephridia and parts of the body associated with balance called stato cysts [1].
Parasitologically, leeches are of dual concern. Some are parasites and others are involved in life cycle of other parasites. Leeches are vectors of protozoans such as Trypanosome, Cryptobia, Haemogregarina and probably others of fish, amphibians and reptiles. They also serve as hosts, both intermediate and final, for some digenetic trematodes and cestode cysticerci $[3,4,9]$.

The amount of injury caused by leeches is related to the number of leeches present and the amount of blood removed [4]. Traditional method of treatment of animals before they are infested by leech is practiced by farmers [2].

The objectives of this paper are:

- To review the general characteristics of leeches.

- To highlight the pathogenic and beneficial effects of leeches on human, domestic and wild animals.

\section{A Review on Leech}

\section{Types of leech}

There are different types of leech, on which their types is varied depending on ways by which they feed. Order Gnathobdellidae and Rhynchobdellidae are mostly orders of leech, based on whether they have jaws or not on their sucker. In the Gnathobdellidae the anterior sucker contains the oral aperture, which is provided with three strong toothed jaws. The number of teeth can be hundreds which are found on the cranial sucker. Members of this order are also known as "Jawed" leeches. The European medicinal (blood sucking or sanguivorous) leech, Hirudo medicinalis, is under this order, while the order Rhynchobdellidae have a protrusible proboscis, but no jaws. The species of medicinal and veterinary interest belongs to the order Gnathobdellidae [1].

Pharyngobdellidae worm leeches consist of fresh water or amphibious leeches that have lost the ability to penetrate a host's tissue 
and suck blood. They are carnivorous and equipped with a relatively large, toothless, mouth to ingest worms or insect larvae, which are swallowed whole. They have six to eight pairs of eyes, as compared with five pairs in Gnathobdelliform leeches, and include three related families, the Erypobdellidae are some species from fresh water habitats [12].

Haementeria officinalis and Placobdella catenigera have proboscis instead of jaws that can be inserted in to the body of host to suck blood. Limnatis nilotica cannot penetrate skin but on being taken in with water by men and animals it attaches itself to the buccal mucus membrane. Haemadipsa zeylanica is another leech which is small form, but are very serious pests [13].

\section{Morphology}

Leeches have slender leaf shaped bodies that lack a locomotory organ, bristle like structure called setae (chaetae) and Para podia or appendages. Instead of this locomotory organ, the leech possesses two suckers in each extremities, a large adhesive posterior sucker and a small anterior sucker. As a member of phylum annelida, the leech is segmented and lacks a hard exoskeleton; in its place the leech has a thin, flexible cuticle. Because of this thin cuticle, leeches dry out quickly and must always be closely associated with water [9].

Unlike those of other annelids, the body segments of leeches are not divided in to compartments, and the coelomic space is largely filled with mesenchyme tissue. Therefore, leeches move in a very different manner than other annelids. Groups of segments of each end of a leech are modified to form sucker which serve as temporary anchors. With its posterior anchor attached to the substrate, the leech extends its body by contraction of its circular muscles. The anterior sucker is then attached, the posterior one detached, and the leech shortens itself by contracting its longitudinal muscles [10].

Leeches are generally small but range from 10 to $15 \mathrm{~cm}$ long. But fully grown specimen may be 30 to $35 \mathrm{~cm}$ long [2]. The ectoparasite, leech range in size from tiny species that are $5 \mathrm{~mm}$ long to varieties such as Haemopis, which have been reported to be as long as $45 \mathrm{~cm}$ when extended and swimming [9]. The body of the leech is brightly coloured with characteristic markings and the dorsal surface is olive green [2].

Limnatis nilotica (horse leech) is $8-12 \mathrm{~cm}$ long and its body is soft. The dorsal surface is fairly dark brown or greenish and usually has several longitudinal rows of black spots. The ventral surface is darker than the dorsal and there is frequently an orange band on either side. The anterior lip has a longitudinal groove on its inner surface [1]. The setae which is used for anchoring is absent in all but one species of the leeches [14].

The number of annuli per segment in the mid body region is typical for any given species, three and five being commonest; but the number of annuli comprising the terminal segment is reduced. Eyes commonly vary from one to five pairs, placed anteriorly. The clitellar region which secretes the egg cocoon extends from segment ten through twelve and contains the male and female genital openings. The structure of an anterior portion of leech constitutes one of the most important taxonomic characters for dividing the class in to two orders: aproboscidal (order Arhynchobdellae) and proboscidal (order Rhynchobdellae) leeches. In the first group the buccal sinus is restricted chamber housing the jaws (when present), and in the latter a space around the pharynx, which is there by freed as a protrusible proboscis [7].
The excretory organ of leech is composed of 17 pairs of nephridia. The circulatory system has no distinct blood vessels; instead, there are six blood sinuses. The two lateral sinuses have a muscular wall and function as hearts to circulate the blood [4].

\section{Geographic distribution}

Leeches classified under the phylum Annelida to the class Hirudinea, are of world wide distribution and are extremely abundant both in species and in the number of individuals. The common leech Hirudinaria manillensis of the Philippines is said to play the role of carrier of the pathogenic organisms of Rinder pest disease [2].

The terrestrial, or land varieties of leeches are found in the tropical regions of the world, particularly, South East Asia, the Pacific Islands, the Indian sub continents, and South America. Land leeches are found on the surface of trees and grasses and under stones in damp places. One terrestrial leech, Haemopis terrestris, has been plowed up in fields in the mid western United States [9].

Haementeria officinalis, which is found in South America have proboscis instead of jaws. Placobdella catenigera, occurring in the Mediterranean region, also attacks man and domestic animals. Limnatis nilotica is found in North Africa, and Southern Europe. Haemadipsa zeylanica, found in Asia lives on land attacking all vertebrates and many different species of mammals have been killed by them through sheer loss of blood [13]. Throughout the Mediterranean area and the middle and Far East regions, certain leeches are injurious to animals and humans [7].

\section{Habitats of leech}

Leeches are blood sucking, predatory or scavenging ectoparasites of both human and domestic and wild animals found in marine water; a few terrestrial, or land. Leeches are also found in the moist damp locations. For the most part, leeches should be considered as aquatic animals [9].

Fresh water leeches prefer to live in still or slowly flowing water, but specimens have been collected from fast flowing streams. Some species are considered amphibious as they have been observed in both terrestrial and aquatic habitats [15].

As a result of these different habitats, leeches have developed two widely different habits, namely, swimming and stepping. Swimming is the method of locomotion used when the leech is in water. At this time, the leech's body becomes flattened dorsoventrally as waves of muscular contraction pass down its length. The result is an undulating motion that propels the leech forward. Stepping is a method of locomotion used when the leech is on solid ground. In this mode, the leech moves in an "inch worm like" fashion using its cranial and caudal suckers as organ of attachment. The layer of circular muscle just beneath the epidermis contracts, and the leech becomes long and thin. The cranial sucker then attaches to the substrate, the caudal sucker releases, and the longitudinal muscle layer beneath the circular muscular brings the caudal sucker up to the vicinity of the cranial sucker, where it attaches. The overall effect is "stepping" [9].

A leech moves by attaching its head to the surface, bringing its tail up to its head briefly, and then, releasing the head end and pushing it forward again [16]. Ubiquitous aquatic leeches that parasitize fish, frogs, and turtles readily attach to the skin of humans and avidly suck blood. More notorious are the land leeches (Haemadipsa) that live in moist vegetation of tropical rain forest [17]. 


\section{Life cycle}

Leeches are hermaphroditic; because each individual of leech male and female organs are located on adjacent body segments. Self fertilization is impossible and cross fertilization must take place. They copulate to bring about cross fertilization and both partners become fertilized [9]. Soon after fertilization, eggs are laid in cocoons secreted by the clitellum, which extends from the median male genital opening on the tenth segment through the median female genital opening on the eleventh segment [1].

Leeches have an annual life cycle. They mate in the spring; young leeches develop and mate in the spring of the following year. Eggs in cocoons are deposited in damp soil [4]. The cocoon of each species of leech has a characteristic shape and design. Hirudo medicinalis, the medicinal leech produces from one to seven cocoons, each of which may contain five to fifteen eggs. Depending on the species of leech, cocoons may be attached to the parents body or adhere to solid surfaces with in the aquatic environment. Young leeches hatch from the eggs, feed for a few days on the yolk, and develop to the adult blood sucking mode. Adult leeches can live for as long as 18 to 27 years [9] (Figure 1).

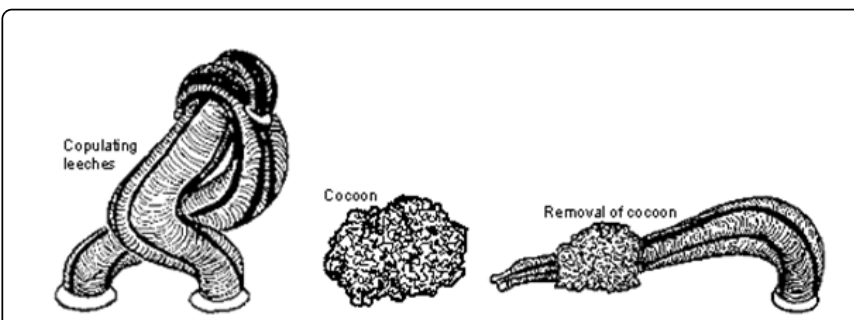

Figure 1: Cross fertilization and deposition of cocoon in leeches [12].

\section{Feeding}

The majority of leeches are blood sucking (sanguivorous) or blood feeding ectoparasites on a variety of hosts, but about $25 \%$ of the species are predators of small invertebrates. Most predatory leech feed on worms, snails, and insect larvae. Their prey is either swallowed whole or the leech may simply suck the soft parts $[3,4]$.

Most leeches are adapted for living on the blood of vertebrates. A leech can store large amounts of blood in the side pouches of its intestine. Their digestive system is adapted for the storage of huge quantities of blood $[5,16]$.

Blood sucking leeches feed infrequently, but take an enormous amount of blood when they do. They normally take two to ten times their own body weight and need feed only twice a year [4]. The liquid can then be stored for months, as portions are gradually passed into the intestine for digestion and absorption [5]. They secrete only exopeptidases and need the help of gut bacteria such as Pseudomonas hirudinicola to aid digestion of proteins in the blood into amino acids which are subsequently used by both leeches and bacteria [4]. During a single feeding period, a terrestrial leech such as Haemadipsa may ingest ten times own weight and Hirudo two to five times its own weight. Then it may take the leeches up to 200 days to completely digest this large meal that it takes from the host. These leeches are reported to have gone without food for as long as 18 months [3].
A hungry leech is very responsive to light and mechanical stimuli. It tends to change position frequently and explore by head movement and body waving. It also assumes an alert posture, extending to full length and remaining motionless. This is thought to maximize the function of sensory structures in the skin. In response to disturbances by an approaching host, the leech will commence "inch worm crawling" continuing in a trial and error way until the anterior sucker touches the host and attaches. Jawed leeches have semicircular and many toothed jaws like minute saws. Using these it makes an incision in the skin and excretes mucous from the nephropores (external openings from kidney - like organs), which helps the sucker to adhere. A salivary secretion containing the anticoagulant and histamine floods the wound and the leech relaxes its body to allow the blood to be ingested. This mixture allows the blood to flow and also prevents clotting once inside the leech [15] (Figure 2).

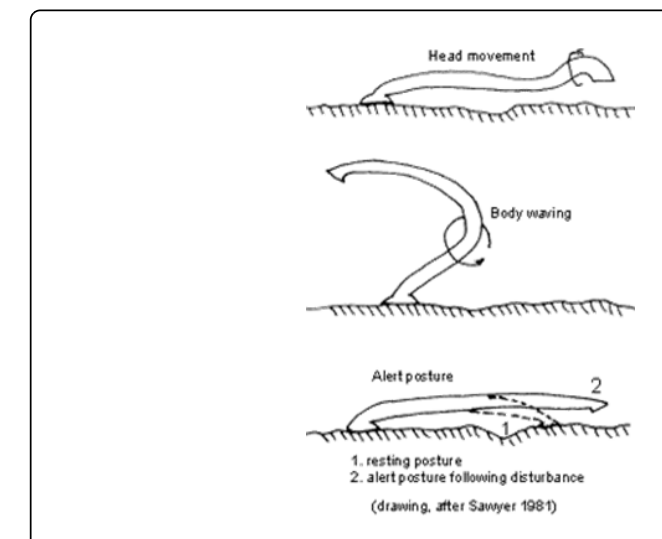

Figure 2: Leeches searching for a blood meal [15].

\section{Pathogenesis}

Leeches have a terminal sucker for locomotion and attachment. Blood sucking species fasten to the skin or oropharyngeal mucus membrane by means of their powerful suckers, pierce the epidermis, and suck blood. A salivary enzyme, hirudin, secreted by jawed leeches or Gnathobdellidoe, acts as an anticoagulant and ensures a copious flow of blood [18]. Jawless leeches or Rhyncobdellidae insert a needle like protrusion called a proboscis in to a body of the host and secret an enzyme, hemetin which dissolves clots once they have formed. Leeches which live on body fluids of worms and small fresh water snails possess such an apparatus [12].

While the leech is attached to the host with its caudal sucker it uses cranial sucker to explore the hosts skin to locate a suitable feeding site and to attach tightly. Three rows of jaws with approximately 100 teeth are found within the cranial sucker. These operate in a manner similar to circular saw, penetrating through the skin to a depth of $1.5 \mathrm{~mm}$. The wound produced by leech bite is a characteristic y-shaped skin incision. When incision is made very little pain is felt by the host. The ability of leech to feed is made easier by the secretion of powerful anticoagulant into the site of attachment. Histamine like substance is added to the wound to prevent the collapse of adjacent capillaries. As the blood passes through the mouth, the anticoagulant, hirudin, is added to it. Hirudin is a 64 -amino acid peptide that functions like antithrombokinase. It has been described as the most powerful anti coagulant known. Active agents in the saliva of various species of leeches include a hyaluronidase, a collagenase, and two fibrinoses [9]. 
The leech attaches its sucker near the site of injury, makes an incision, and deposits anticoagulants, hirudin, which prevents the blood from clotting and dissolves already existing clots. In 30 minutes, a leech can suck out as much as ten times its own weight in blood [11]. If attached leech on the skin is pulled off, they may leave their jaws in the skin; and induce ulceration and serve as site of infection [9].

Small fasted leeches, taken in with drinking water, reach the laryngopharynx region, or may enter the nasopharynx, and became attached. By sucking blood, they increase, greatly in size, cause congestion and inflammatory swelling, and may occlude the passages involved. In some countries this condition is known as halzoun. Not only may the host be killed or left in an emaciated condition as result of heavy infestation, but the value of commercial and game fish may be materially impaired as a result of the inflammation developing where the leeches have attached. These breaks in the mucosal covering resulting from attachment may serve as a portal of entry for microbial organism, which cause secondary infection. The Glossphoniid theromyzon commonly enters the nares of water fowl often resulting in asphyxiation [7].

\section{Clinical signs}

Pharyngeal leeches feed on blood of cattle and can cause anemia by sucking blood of domestic animals. The presence of leech in the oropharyngeal and laryngeal mucus membrane may cause severe bouts of coughing and chocking. Hirudin leads to a copious flow of blood which sometimes results in anemia and bleeding may continue for some time (up to 2 hours) after the leech has dropped off. Blood or bloody froth may often be discharged from the mouth or nostrils of the animals. There is dyspnoea and in severe cases the neck is extended and the mouth is held open. Edematous swelling may be seen in the parotid and intermandibular regions. Death may be caused by asphyxia and it may occur suddenly as a result of oedema of the glottis [2].

Depending on the site of attachment, leeches may cause the host to exhibit nose bleeds, cough up blood, or vomit up blood. A leech attached in the laryngeal region may produce a cough with a bloody discharge, difficulty in breathing, pain, and even suffocation. A leech localized in the region of the epiglottis may cause difficulty in swallowing. In sever breathing disturbances, the host's neck may be extended and the animal may exhibit open mouth breathing [9].

Limnatis africana leech taken in drinking infected water may cause debility and marked local disturbances. The species of Haemadipsa tenant are very active and creep in even under tight fitting clothing. Their bite is not painful, but the wounds may bleed for a long time. When they attach themselves to the ankles of human beings or the legs of horse and other animals, severe irritation and anemia may result. Death has been attributed to them, but they are not usually fatal [1].

Roberts described severe keratoconjunctivitis in domesticated geese in Shropshire, England, caused by numerous individuals of the small species [19]. Theromyzon tessulatum, the leech harboured by aquatic birds of the family Anatidae, normally an in habitant of the nasal sinuses, which had attached to the eyes of the geese.

\section{Diagnosis}

Thinking about diagnosis of animals infected with leeches is the method of choice to retrieve animals from leech infestation. Mostly this diagnosis is done following the major clinical signs that the affected animals shows after infestation with leech and observing or finding the parasite in the pharynx and in the skin. In the pharynx, it can be observed by gentle holding of the animal and opening its mouth. An elastic catheter is also use full [1].

\section{Treatment}

The injection of chloroform water (chemotherapy), gives very success full results, but it is expensive. An elastic catheter is passed through the inferior meatus and to the free end a $60 \mathrm{ml}$ syringe containing the solution is attached. The solution is injected slowly while the catheter is revolved, the head of the animal being held in a horizontal position. In extreme cases tracheotomy may be necessary. As prophylaxis, the animals should be watered from clean troughs. Leeches in water can be killed by means of copper sulfate as applied for snails [1].

Leeches can be mechanically removed without damaging the host's tissue. The open wound should be treated with a styptic and an antiseptic [18]. Drops of concentrated salt solution, alcohol, or strong vinegar applied around the mouth of the leech or heat with a lighted match or cigarette applied to the leech's body will cause land leeches to release their host [9].

Trichlorfon (0.25-1 ppm in aquarium water) is effective but is not approved for use in food fish, and environmental regulations may restrict its use in outdoor ponds. Multiple treatments may be used because eggs are resilient and juveniles may continue to hatch [20]. Fish may be treated by immersing them in a solution of neguvon (2-3\%) for 15-30 seconds [1].

\section{Control and prevention}

Avoiding leech (effective quarantine) and depopulating infected aquarium (fish) and ponds are the best control and preventive measures. Infestations in recreational fishing ponds are often selflimiting [20]. Considering the nature of the problem, treating contaminated water body is preferable than treating infected animals. This is because infestation of animals by leech is usually detected after it has caused major parasitic effects [2].

Application of a commercial chemical like copper sulfate and niclosamide to contaminated water is possible but these chemicals are expensive and they are toxic to other non-targeted organisms. Traditionally, farmers attempt to control leech in two ways: targeted at water body and targeted at the animal level. At the water body they add crop residues of nuge, absuda or attela on water before animals drink and they clean the water mechanically. At the animal level, nasal drenching of tobacco and Tinjut leaves crushed together and mixed with water; smoking with animal dung and mechanically pulling out the leech and endod or berbira juice. In recent years, a widely established fact indicates that Endod (Phytolacca dodecandra) has a molluscicidal property and used in the control of human shistosomiasis. The preliminary laboratory trial of the berries of endod showed promising results. A series of studies on the properties of this plant have shown that it has low toxicity, on mammals, micro flora and fauna, rapid biodegradability and stability under different environmental conditions. To utilize this local plant for control of leech, a demonstration trial becomes crucial. Demonstration for the application of endod for the control of leech infestation was done in Sululta and Mullo woreda and it got acceptance that all leeches were died in water threated with endod. The output of the demonstration is that endod applied to watering points with in recommended dose and 
method of application does not show any effect on health and productivity of experimental animals at any age and physiological status [2].

\section{The Medicinal Leech}

People can get leech by direct contact with the leech, when they are bathing or standing in or around the water and encounter hirudiniasis $[20,21]$. Their bite is not painful, but the wounds may bleed for a long time, this is because of the salivary secretion of the leech, hirudin, which keeps the blood not to clot $[1,22]$.

\section{Medical uses of leech}

Leeches used to be widely employed in medicine for blood-letting or for drawing blood from the areas swollen by poisonous stings and bites, for example, to reduce fluid pressures in tissues damaged by, a snake bite, and to eliminate pools of coagulated blood [10,11]. Leech is widely used to treat hematoma, and also used to remove "bad blood "which was thought to be cause of many disease $[8,11]$.

Medical uses of leeches also include treatment of black eyes [22], and hirudin is used in the treatment of inflammation of the middle ear. Hirudin is also being developed for experimental use as a systemic anticoagulant and may prove useful in invitro blood sampling [23].

Several species of leeches have proven to be beneficial to humans. Perhaps the best known leeches used for blood letting is Hirudo medicinalis, the European medicinal leech [9], and there are also other medicinal leeches, $H$. troctina and Haementeria officinalis [13].

The European medicinal leech, Hirudo medicinalis, is still used occasionally to reduce venous congestion in surgical flaps or replanted body parts. This practice has been complicated by wound infections, myonecrosis, and sepsis due to Aeromonas hydrophila, which colonize the gullets of commercially available leeches [17].

\section{Symptoms in human}

When the leeches attach themselves to the ankles of human, they result in sever irritation and anemia, even some leech enter, and cause bleeding from, the vagina or urethra of people bathing [1].

Some people suffer severe allergic or anaphylactic reactions from leech bites and require urgent medical care. Symptoms include red blotches or itchy rash over the body, swelling away from the bitten area (especially around the lips or eyes), feeling faint or dizzy, and difficulty breathing [24]. Some 20 cases of aeromoniasis have been described of infection caused by medicinal leeches, Hirudo medicinalis [25].

\section{Treatment}

Externally attached leeches are removed by steady gentle traction and hastened by application of alcohol, salt, vinegar, or flame to the leech (inadvisable medically). Internally attached leeches may be detached on exposure to gargled saline or removed by forceps. A common but medically inadvisable technique are alit cigarette, soap or caustic chemicals such as lemon juices, insect repellent, heat rub, or certain carbonated drinks. These cause the leech to regurgitate its stomach contents in to the wound, and quickly detach [17].

After removal or detachment, the wound should be cleaned with soap and water, and bandaged. Apply pressure to reduce bleeding, due to leech's anti-clotting enzyme. An antihistamine to reduce itching and applying a cold pack can reduce pain or swelling [24].

\section{Prevention}

There is no guaranteed method of preventing leech bites in leech infested areas. The most reliable method is to cover exposed skin. The effect of insect repellents is disputed, but it is generally accepted that strong insect repellents do help prevent leech bites [24].

\section{Conclusion}

Leeches occur world widely and their infestation increase during dry season. If unwary man or animal drink leech infested water or come in contact with it, they can easily encounter it. Like most ectoparasites, leeches have blood sucking (sanguivorous) habit feeding on the blood of cattle, man and other domestic animals. When leeches got the host they cause local bleeding which is related to pharmacologically active anticoagulant, hirudin, and vasodilator substance, histamine, introduced by the leech bite. Though, the economic loss and other negative impacts of leech is not studied very well in Ethiopia, pharyngeal leeches feed on blood of cattle and can cause anemia. Different modern and traditional ways of treatment of leech are exercised. Leeches can demonstrate both pathogenic and beneficial effects on humans and wild and domesticated animals.

\section{Recommendations}

Considering the nature of the problem, leech infested water should be treated preferably than treating infected animals. This is because infestation of animals by leech is usually detected after it has caused major parasitic effects on animals.

Since chloroform water gives very successful results against leech infestation, it should be applied in highly leech infested areas.

The animal rearing society should be educated about the side effects of leech infestation and the possible methods of early prevention.

\section{Acknowledgements}

We would like to express our keen gratitude to Dr. Kassahun Berhane, for his guidance, material, moral support.

\section{References}

1. Soulsby EJL (1982) Helminthes, Arthropods and Protozoa of Domesticated Animals. 7th edn. Baielliere Tindall, London, pp: 352-355.

2. Legesse W, Tadele W, Bulbula A, Tilaye A, Anbesso S (2006) Control of leech using Endod (Phytolacca dodecandra), Sheraton Addis, Ethio AgriCEFT, pp: 23-36.

3. Bush A, Jacqueline C, Fernandez GW, Esch RS (2001) Parasitism. 1st edn. Cambridge, pp: 44, 297-304.

4. Marquardt L, William R, Demaree S, Robert BG (2000) Parasitology and Vector Biology. 2nd edn. Harcourt academic Press, London, pp: 506- 507.

5. Brum G, Larry M, Gerry K (1993) Biology (Exploring Life). 2nd edn. John Wiley and Sons. Inc., New York, pp: 875-876.

6. Campbell N, Jane B, Reece LG, Mitchell (1996) Biology: Concepts and Connections. Addison Wesley Longman, California, p: 381.

7. Gerald S (1994) Essentials of Parasitology. 4th edn. Universal Book stall, New Delhi, p: 184.

8. Villee CA (1989) Biology. 2nd edn. Saunders College Publishing, Philadelphia, London, pp: 690-695. 
Citation: Aloto D, Eticha E (2018) Leeches: A Review on their Pathogenic and Beneficial Effects. J Vet Sci Technol 9: 511. doi:

9. Henderix MC (1998) Diagnostic Veterinary Parasitology. 2nd edn Mosby, Elsevier (USA), pp: 13, 234-238.

10. Purves WK, Gordon H, Orians H, Craig H (1992) Life: The Science of Biology. 3rd edn. New Delhi, India, pp: 567-568.

11. Solomon EP, Berg LR (1995) World of Biology. 5th edn. Philadelphia, Harcourt Brace College publishers, pp: 462-463.

12. Sawe RT (1981) Neuro biology of the Leech. Leech Biology \& Behaviour. Cola Spring Harbour Laboratory.

13. Geoffrey P, West MR (1975) Blacks Veterinary Dictionary. 11th edn Adam and Charles Black, London, p: 547.

14. Raven PH, George BJ (1988) Understanding Biology. Mosby, St. Louis, Toronto, p: 543.

15. Davies RW, Linton LR, Wrona FJ (1982) Passive dispersal of four species of freshwater leeches (Hirudinoidea) by ducks. Freshwater Invertebrate Biology 1: 40-44.

16. Burton SG (1999) Biology. 1st edn. Mc Graw Hill, New York (Boston), pp 740-741.

17. Kasper L, Dennis MD (2005) Harrison's principles of internal Medicine. 16th edn. McGraw-Hill, New York, p: 2602.

18. Bowman DD (2003) Georgi's Parasitology for Veterinarians. 8th edn. Saunders, Elsevier, USA, p: 233.
19. Roberts HE (1955) Leech infestation of the eyes in geese. In: Soulsby EJL (eds.) Helminthes, Arthropods and Protozoa of Domesticated Animals, Baiellire Tindall, London, pp: 352-355.

20. Merck J (2005) Merck Veterinary Manual, 9th edn. Merck and Co., Inc. Merck and Aventis Company, pp: 1504, 1608, 2568-2569.

21. Bill F (1999) Where There Is No Vet, 1st edn. Macmillan Press LTD, London and Oxford, Hong Kong, p: 175.

22. Bernstein L, Martin S, Alan W, Stanley W (1998) Concepts and Challenges in Life Science, 3rd edn. Globe Fearon, New Jersey, pp: 176-177.

23. Seliznev KG Shchetinina EA, Trophimenko NP, Nikonov GI, Baskova IP (1992) Use of the medicinal Leech in the treatment of ear diseases. ORL J Otorhinolaryngol Relat Spec 54: 1-4.

24. Ibrahim A, Hakim BG, Mohd NB (2003) An unusual cause of vaginal bleeding: A case report. The Internet Journal of Gynecology and Obstetrics 2: 2 .

25. Acha N, Pedro B (2001) Zoonoses and communicable diseases Common to man and animals. 3rd edn. Pan American Health Organization, Washington DC, pp: 8,9,12. 